\title{
Ars longa, vita brevis
}

\section{Last remaining astronomy department disbanded.}

\section{James Alan Gardner}

9 November 2270: In a move described as "long overdue", the Astronomy department of the University of California, Berkeley, has been dissolved. Faculty and students from the defunct department will be shifted into other areas of the university, particularly sociology and fine arts. Berkeley's astronomy programme was the last of its kind at any major educational institution.

"We tried to keep the place going," said former department chair Dr Jeremy Washburn, "but with Astronomy departments folding in so many other universities, we knew it was just a matter of time. The enthusiasm just isn't there anymore.

"I confess," Dr Washburn continued, "I understand how other people feel. Celestial mechanics really lost its charm when we learned all the interesting stuff is artificial."

Dr Washburn was referring to revelations from advanced extraterrestrial races that they are personally responsible for prominent astronomical phenomena. For example, the Vingex of Betelgeuse claim to have created all the binary and trinary solar systems in our galaxy by dragging stars closer to each other.

"It makes for more attractive visual composition," said Speaker 183-478D, cultural attaché to the Vingex embassy on Earth. "Which is more interesting: a single sun just sitting in the middle of nowhere, or a group of colour-coordinated suns that set each other off nicely against the black background?

"And it's even better when you add a few planets to weave in and out between the stars. The orbits aren't stable gravitationally, but you can keep them in line with a..... Here the Speaker's translator implant whistled several times, representing an untranslatable word - presumably the name of a Vingex device for adjusting the orbits of wayward planets.

Later in the same interview, Speaker 183478 D repeated the Vingex's offer to procure a binary companion for Sol, Earth's own sun. While the Speaker declined to say which star might be chosen as a suitable partner for Sol - "we want it to be a surprise" — hints were given that the star is blue-white, well-established in the main sequence, and "seldom given to solar prominences or other unattractive outbursts".

When asked to comment on the Vingex offer, Dr Washburn said it was just the sort of thing that had taken the fun out of astronomy. "There was a time when we'd have been fascinated by a blue-white sun locked close to a yellow one like Sol. It would have been worth a few review letters and perhaps a $\mathrm{PhD}$ thesis. Now it tells us more about the Vingex's aesthetic sense than it does about stellar evolution."

The Vingex are not the only race involved in large-scale cosmological manipulation. It is well known, of course, that Homo sapiens first made contact with alien life-forms when a group of Pleonines arrived in our solar system to "freshen up" the rings around Saturn and other outer planets. According to the Pleonines, several millennia had passed since the rings last received any touch-up work; colours were badly faded, and visual appeal had suffered.

During the restoration work, the Pleonines demonstrated techniques for creating new rings, as well as simulating colours through diffraction and producing complicated "braid" patterns. They also added two more giant red spots to Jupiter's atmosphere and moved Pluto four billion kilometres closer to Earth because humans were having trouble seeing it where it was.

"We enjoy giving others the chance to view our work," the Pleonine Queen explained. Although members of her race are primarily interested in expressing themselves through planetary rings and giant atmospheric anomalies, Her Majesty has adorned the entire surface of Pluto with a portrait of herself, created by meteorite collisions. The portrait appears to be rendered in the style of the early Cubists; in the Queen's case, however, this may actually be photo-realism.

Once the Pleonines had 'broken the ice' by making contact with humankind, other aliens soon arrived to ask our opinion of their art. Notable amongst these visitors were the all-mechanical Regimoids, creators of every pulsar in the universe ("pulsars ... are ... regular ... pulsars ... are ... beautiful ..."), the Über-Masons who constructed the Great Wall, and the so-called Bangers responsible for supernovae.

"Oh yes," said Dr Washburn of Berkeley. "I knew our department was in trouble when I heard about supernovae. We had all those great theories about stellar collapse ... then suddenly, we found out novae were just the work of ET punks who liked blowing things up. The very next day one of our best Astronomy professors transferred into Humanities. She still gives the same slide show she did in Astro 101, but now it's called Art History.

"That was discouraging enough," continued Dr Washburn, "but the thing that broke my heart was those jelly people showing up to take credit for the Horsehead Nebula. I can still remember their words: 'My God, from this angle it looks fabulous!'” Dr Washburn sighed. "I used to think it did too."

Shaking his head sorrowfully, Dr Washburn cleared his desk, left his office, and locked the door behind him.

James Alan Gardner studied applied mathematics at the University of Waterloo, and then immediately began writing science fiction instead. He lives in Kitchener, Ontario, Canada; his novels include Commitment Hour, Expendable and, most recently, Hunted (Eos).
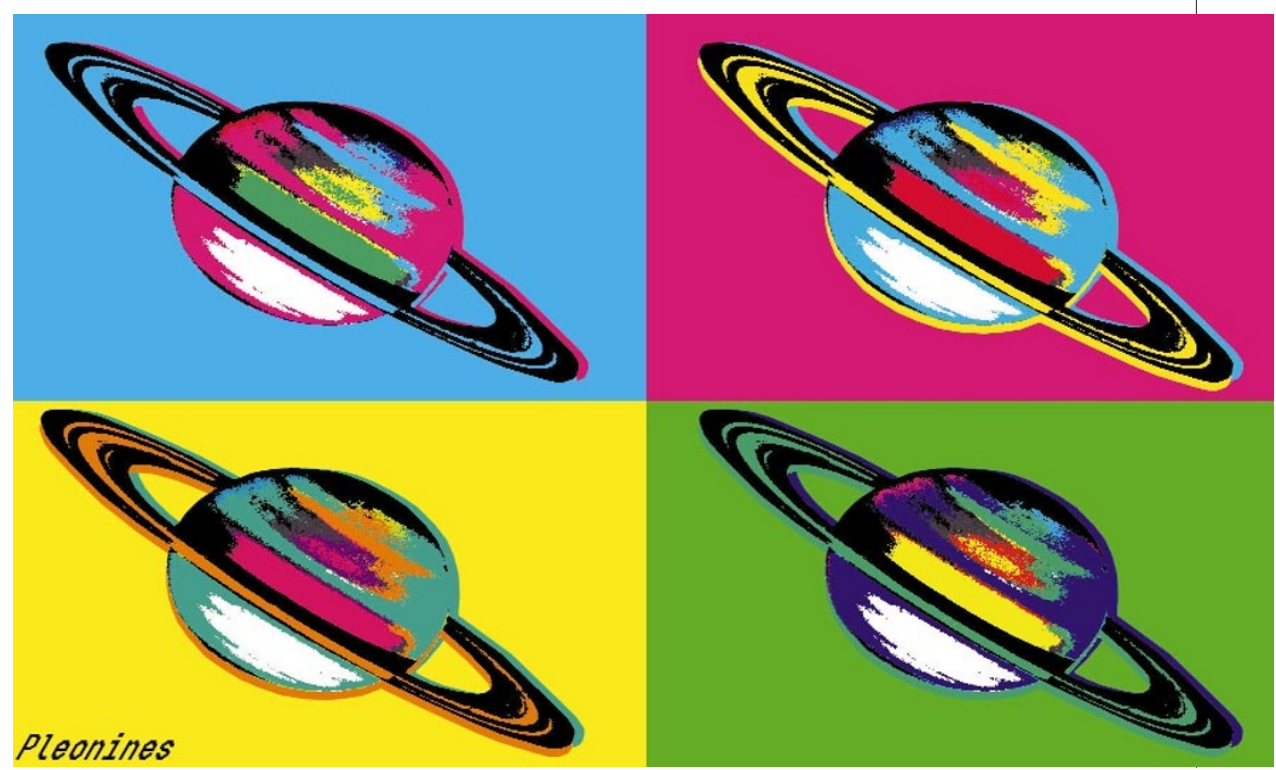